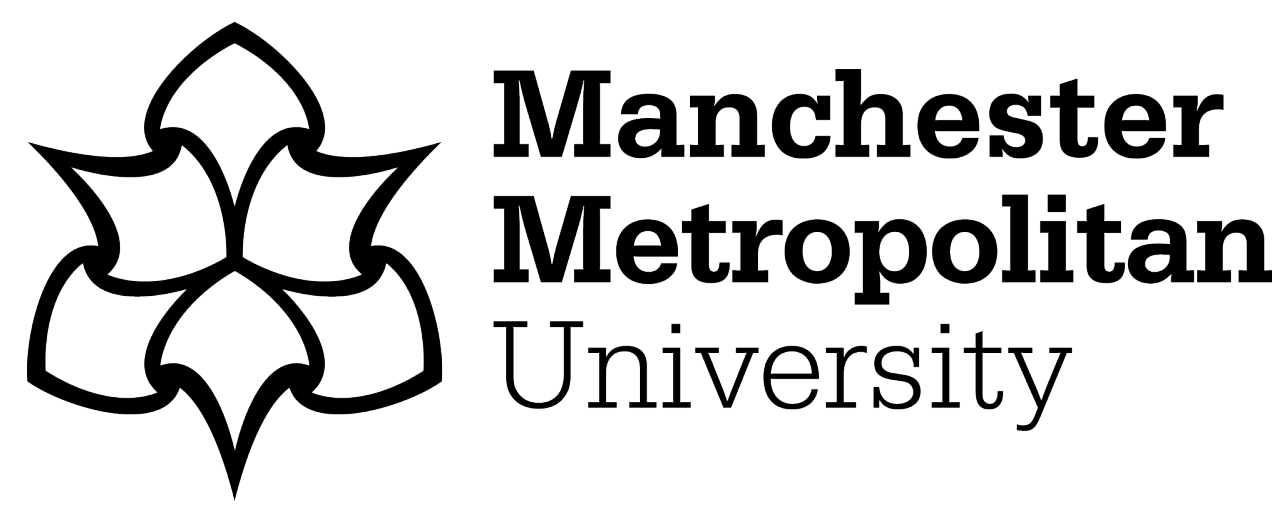

Jack, Kirsten, Hamshire, C, Harris, W, Langan, A. M., Barrett, N and Wibberley, Christopher (2018) 'My mentor didn't speak to me for the first four weeks': Perceived unfairness experienced by nursing students in clinical practice settings. Journal of Clinical Nursing, 27 (5-6). pp. 929-938. ISSN 0962-1067

Downloaded from: https://e-space.mmu.ac.uk/618958/

Version: Accepted Version

Publisher: Wiley

DOI: https://doi.org/10.1111/jocn.14015

Please cite the published version 


\section{'MY MENTOR DIDN'T SPEAK TO ME FOR THE FIRST FOUR WEEKS': PERCEIVED UNFAIRNESS EXPERIENCED BY NURSING STUDENTS IN CLINICAL PRACTICE SETTINGS.}

\section{ABSTRACT}

\section{Aims and Objectives}

To explore the perceived unfairness experienced by student nurses during their undergraduate clinical placements.

\section{Background}

It is important that student nurses feel supported by practice staff during their clinical placement education experiences. However, it has been reported that learners can feel ignored, unsupported and bullied by others in the clinical environment and this has a detrimental effect on their learning. It is important to understand the student nurse perspective and explore ways in which their feelings of belongingness might be enhanced in the clinical area.

\section{Design}

A descriptive narrative approach was utilised to explore qualitative data generated by the survey and interviews. Limited closed question survey data is presented quantitatively as percentage responses to relevant placement and mentorship issues.

\section{Methods}

A survey was conducted with 1425 student nurses from adult and mental health degree nursing pathways, across 9 institutions in the North West of England, UK. Unstructured interviews were undertaken with 22 student nurses from across these 9 
institutions. The data generated from both methods (free text survey responses and interview) were thematically analysed.

\section{Results}

There were times when student nurses felt that they had been treated unfairly by various members of the health care team during their clinical placements. Unfairness was related to being ignored and unsupported or being used as an 'extra pair of hands' and having their supernumerary status ignored. Student nurses want to have feelings of belongingness in the clinical area and value enthusiasm for teaching from mentors. Certain positive mentor qualities were identified through the data in this study. These have been used to inform a tiered model of mentorship, to inform future thinking about student nurse education.

\section{Conclusion}

Student nurses can feel like they are being treated unfairly in the clinical area in numerous ways. Identifying ways in which mentorship practice can be developed to adequately support education is important. This can lead to satisfaction and development on both sides of the student/educator relationship.

\section{Relevance to Practice}

Exploring student nurse perceptions of their learning is important when attempting to enhance educational practice in the clinical setting.

\section{KEYWORDS}

Education, leadership, learning, mentorship, model, practice, student nurse, support, unfairness. 


\section{INTRODUCTION}

Placement learning is an essential part of undergraduate nursing preparation and comprises $50 \%$ of the overall undergraduate programme hours in the United Kingdom (UK) (NMC, 2010). This clinical preparation is similar to that found in Europe, the USA and Australia (Saarikoski et al 2007). Learning in the clinical practice setting, not only offers opportunities for skills development but is an important part of the socialization process and can support decision making about future career choices (Ion et al, 2017). Clinical practice experiences have the greatest influence on students' desire to remain on their programme and negative experiences are linked to attrition and stress (Crombie et al. 2013; Hamshire et al. 2013a).

Historically, student nurses were socialized to be obedient, respect authority and conform to, rather than question, the ways of clinical practice (Levett-Jones and Bourgeois, 2008). Latterly, supported by the move to an all graduate profession, the aim of nurse education has altered. Rather than conform to cultural norms, today's student nurse is encouraged to think critically, question practice NMC 2010) and take a role in the monitoring of care standards (Francis 2015). The NMC stated that

'Nurses must be equipped to lead, delegate, supervise and challenge other nurses and healthcare professionals. They must be able to develop practice, and promote and sustain change. As graduates they must be able to think analytically, use problem solving approaches and evidence in decision-making, keep up with technical advances and meet future expectations' (NMC, 2010: pg. 4) 
To meet this altered aim of nurse education, students require positive placement experiences, facilitated by effective mentorship. However, students experience variability in clinical placements, which are not always described as positive or conducive to learning; and may result in a loss of self-esteem and subsequently their authentic self (Randle, 2002). Thus rather than question practice, they might be more likely to try to fit in, in order to complete the placement successfully.

This paper will present and discuss selective qualitative findings from a regional mixed-methods inquiry, which explored students' perceptions and experiences of health care programmes in the North West of England, UK. It will focus on data relating to perceived unfairness, reported by student nurses, during their clinical placement experiences; as it is these negative experiences that are problematic, despite many students reporting that they have experienced positive experiences on placement as well. Thus the overall aim of the article is to explore the perceived unfairness experienced by student nurses during clinical placements in healthcare settings

\section{BACKGROUND}

Clinical placements are central to health professionals' education, providing a realworld environment in which students can contextualise the theory and skills they have been introduced to in academic settings. However, it has been previously identified as fraught with problems (Levett-Jones et al., 2009) and a source of considerable stress (Bowden, 2008; Timmins and Kaliszer, 2002). Negative placement experiences can cause students to reflect on their choice of career (Bowden, 2008; Brodie at al., 2004; Hamshire et al. 2011) and personal emotional 
resilience is essential (Beauvais et al., 2014; Jones-Schenk and Harper, 2014; Williamson et al., 2013).

However, despite a considerable body of literature exploring placement learning within health professionals' education there is limited evidence available on what exactly makes a good placement. Belongingness (the sense of inclusion within the organisational culture in which they the student is learning) has been identified as important (Levett-Jones and Lathlean, 2008); and a supportive relationship with mentors whilst undertaking clinical placements is essential (Crombie et al., 2013; Hamshire et al., 2011). Yet it is still unclear how placement environments can optimise learning experiences to enhance students' belongingness and social wellbeing (Levett-Jones et al., 2009). Further, it is not only the clinical environment which contributes to the overall student experience. Personal factors, such as family circumstances and financial issues can have a negative impact and can contribute to students discontinuing the course (Knight et al, 2012). Attrition from nursing courses might have a negative impact not only on the student themselves but also on the wider profession. The UK National Health Service (NHS) is witnessing a nursing shortage, which has in turn led to a substantial rise in the employment of agency staff and overseas nurses (NHS Improvement 2016). Therefore supporting students effectively both during their education and on qualification is of great importance.

Levett-Jones et al (2009) described the fundamental importance of positive relationships in clinical practice and suggested that staff play an essential role in the socialisation of students into the workforce. It is often the relationships between student nurses and staff, which have the most impact on the learner and their development. However, students do not always have positive experiences during clinical placements, a situation that has endured over a long period of time. Over 
twenty years ago Meissner (1986: p. 52) asked the question 'Are we eating our young?' suggesting that 'an insidious cannibalism' could potentially destroy the nursing profession from the inside, more easily than any potential external force. She suggested that educators, both in clinical and academic settings, have more of a focus on judging students than they do on supporting them, giving them unrealistic study loads and mocking their idealistic view of nursing.

Randle $(2002,2003)$ has reported on how clinical experiences affected the development of self-esteem in student nurses and found many students ended their nursing programme with lower than average self-esteem. She described a bullying culture, one in which student nurses felt powerless to challenge others due to their junior status. Ultimately students change their behaviours, in order to fit in with the prevalent culture, being unable to express their true thoughts and feelings for fear of reprisals (Jack \& Wibberley, 2014). There is evidence that bullying is viewed as an acceptable aspect of the nursing profession (Nicoreta \& Clinkscales, 2010) and 57\% of nursing students report that they have experienced 'horizontal violence', a form of bullying from within their own professional group, during their programme (Curtis et al, 2007).

Thomas \& Burk (2009) found multiple 'Injustice Incidents' in their study of junior student nurses who described behaviours such as being ignored, disbelieved and humiliated by qualified staff. Thomas et al (2015) described the stressful transition experienced by first year student nurses entering their first clinical placement and having to deal with professional incivility from other members of staff. Student nurses often feel devalued and disempowered during clinical placements, which has a negative effect on their learning and increases the chances of them leaving their nursing programme (Bradbury-Jones et al, 2010). However it is not only student 
nurses who feel disempowered. Daiski (2004) suggested that nurses' relationships with one another are disempowering and along with Thomas and Burk (2009) concluded that the status of nursing as a group within healthcare settings is oppressed by the hegemony of medicine.

Roberts (1983) has also suggested that nursing demonstrates the behaviours of an oppressed group, in response to its domination by medics and hospital administrators and this is not helped by its lack of identity. However, rather than oppose the oppressors, they turn in on their own group, especially those of a lesser status (Daiski, 2004). It would seem then that student nurses are prime targets for horizontal violence, not only because of their status but also because of their difference; today's student nurses in the UK are studying at degree level in contrast to many senior staff, who were educated using the apprentice style model. Intergenerational problems are likely not least due to communication differences and stereotyping of junior staff (Williams \& Nussbaum, 2001). An example of such stereotyping being the belief of some, that student nurses are 'too posh to wash', following on from a motion presented at the Royal College of Nursing Conference and subsequently discussed in an article published in The Telegraph (Hall, 2004).

\section{METHOD}

This paper reports on selected findings of an overarching repeat study that had the aim of identifying factors that contributed to students' decisions to stay or leave commissioned health care programmes in the North West of England, UK (Hamshire et al. 2017). The study utilized a mixed-methods approach, combining both quantitative data from a survey with qualitative data from interviews and the survey the survey forming phase 1 of the study and the interviews phase 2 . The online 
survey used in phase 1 was one used in a previous study of students on commissioned health care programmes (with the survey being developed from narrative interviews carried out as part of this previous study), (Hamshire et al. 2013b). The second phase of the study further explored students' perceptions and learning experiences using narrative telephone interviews in which students were encouraged to tell their stories, beginning wherever and however they felt was most appropriate (see Gubrium, 1993). 1425 student nurses completed the phase 1 survey from across 9 institutions, and 22 student nurses were interviewed as part of phase 2 of the study from across these 9 institutions.

Both datasets (quantitative data derived from the survey and qualitative data derived from both open questions on the survey and from the narratives in the interviews) described a range of experiences both within the clinical environment and whilst on campus. As noted above this paper focuses on a subset of data which relates to perceived unfairness, reported by student nurses, during their clinical placement experiences; as it is these negative experiences that are problematic, despite many students also experiencing positive experiences on placement (see Hamshire et al., 2011). Whilst data were collected from a range of health care profession students for the overarching study, only the data collected from nursing students are utilized in this paper.

Descriptive statistics were used in the analysis of relevant closed question survey data (pertaining to placement experiences); and thematic analysis of the qualitative data, undertaken utilizing a process similar to framework analysis (Ritchie \& Spencer 1994; Spencer, Ritchie et al. 2013). Both Ritchie and Spencer (1994) and Srivastava \& Thomson (2009) have suggested that framework analysis is a useful approach to adopt when inductive (data driven) analysis is used alongside analysis based on a 
priori issues. Data relating to placement experiences (an a priori issue) were read and re-read and emerging themes noted using a constant comparative approach. Phases of familiarization and indexing led to the development of a thematic framework, discussed and agreed between the authors. The transcripts were considered individually by $\mathrm{KJ}$ and $\mathrm{CH}$ and then subsequently discussed until mutual consensus about the meaning of the data was reached between the two researchers. This process supports the credibility of the research along with the inclusion of rich data excerpts (Sandelowski, 1993).

\section{Sample}

The sampling frame for phase 1 of the study (for the purpose of this paper) consisted of all nursing students studying on pre-registration NHS North West commissioned programmes at the time of the study and those who had had discontinued from such programmes during the previous 12 months (from across 9 institutions). Students who completed the survey $(n=1425)$ were asked if they were willing to participate in a follow up interview and from the 439 nursing students that volunteered, 22 were selected via a stratified sampling method.

\section{Ethics}

Ethics approval was obtained from the Manchester Metropolitan University Research Ethics Committee. The information contained in this application, along with the committee decision, was made available to all of the participating institutions who had an opportunity to review the paperwork to ensure that it was commensurate with their own ethics processes. An information sheet was made available for students on a project website. Students had six weeks to consider whether or not they wanted to 
take part in the survey and all students who completed the survey were subsequently invited to be interviewed. Subsequently those students who completed the survey were invited to participate in a telephone interview.

\section{RESULTS}

An analysis of the closed questions on the online survey demonstrated that the students had a generally positive perception of their placement experiences:

- $67 \%$ of students agreed that they felt 'respected on placements'.

- $61 \%$ agreed that they had 'enjoyed' all of their placements to date.

However:

- $59 \%$ agreed that their 'mentors did not have time to teach students'.

- $59 \%$ agreed that they felt they were 'used as an extra pair of hands'.

All students agreed that a supportive mentor was essential to guide learning during their clinical placement.

Thematic analysis of the open questions on the survey and the interview transcripts identified multiple occasions when students felt they were being treated unfairly. Four dominant themes emerged from the data: being used as a 'free pair of hands'; feeling ignored and unsupported; the importance of an effective mentor; and oppressive nursing cultural practices - these four themes are discussed below.

\section{'A Free Pair of Hands'}

During their clinical placements, many students described being used as a member of the ward team and their supernumerary status was not respected. The following 
student described an understaffed area in which students were required to work at the weekend, even though their mentor was not present:

As much as the NHS does not want to admit it, a lot of placement areas given to students are understaffed and seem to utilise students on placement as staff on the floor... particularly you will find that a mentor will be off for a weekend and knowing that they will be short staffed, they will try and put the student on most or all weekends, to help the staff on the floor.

For the following students, being counted in the team numbers had a negative consequence on their ability to learn and meet their placement competencies. Being expected to help out with ward duties can overshadow the fact that students need to learn specific things on each placement:

I felt on most of my placements that student nurses were used as free health care assistants and not given the opportunity to learn what a nurse does. Ward managers, sisters, nurses and HCAs need to be told that student nurses are just that, nurses, and not a free pair of hands to do the work of a HCA.

I feel as students we are used as extra help or HCAs I don't mind that but I spent years as a HCA and I need to learn skills to assist me as a qualified nurse. It doesn't help when mentors aren't interested or don't have the time. In placement thy use us for menial tasks that are not always related to our learning outcomes, like can you go to the shop, make a brew, go to the control room to pick up medicine. I feel like an office junior rather than an intelligent woman studying a professional qualification. 
Certain HCAs will always complain about you, for example, "you've not helped us all morning" - students will help HCAs as much as they can but at the end of the day we are there to work with and shadow a nurse... Other staff members sometimes think we are there for their benefit, and forget that we actually do not get paid and it is our own learning experience [showing a] lack of respect for the student and their need to learn.

For the following student, not only was she expected to complete the work of a HCA, at the cost of meeting her learning objectives, but she felt she was treated poorly and objectified by this particular staff group:

HCAs are often the worst for expecting students to help them with their job despite having competencies to attain. Students are looked at as 'objects', irrespective of life experience, you are 'just a student \& fresh faced'.

\section{'I felt ignored and very unsupported'}

In contrast to the comments above, rather than being expected to work as a member of staff, the following students often felt like they were being ignored and unwanted in the placement area. Rather than being asked to carry out tasks, which might not be related to their learning, the following students endured uncomfortable and unsupportive environments. This is particularly difficult for students with no previous experience of the clinical setting. The first student was ignored for so long that she finally challenged her mentor's behavior: 
My second placement was a horrendous experience. My mentor didn't speak to me for the first four weeks. Eventually I asked her if she wanted to be my mentor and she said she did. I found the feedback from her was poor and when I challenged it I was accused of being rude.

Some of the placements as a student I felt ignored and very unsupported especially as I had no previous experience in an acute hospital setting.

The following excerpts describe experiences relating to ineffective mentorship. These include poor understanding of the students learning style, the use of techniques to avoid teaching and lack of enthusiasm for the mentorship role:

There are a lot of very rude and highly critical staff on wards that make it very clear they do not want students with them or on the placement. Most nurses on placements, particularly when they are not a mentor or recently qualified, do not have any insight or understanding of individual differences and that people learn differently; they expect you to have a certain learning style and personality. If you are not like this then they think that you are rubbish and are only critical about you. Placements quite often don't understand our paperwork or what is expected of us.

On placement, I have had staff tell me that I will learn this job properly once I actually start employment. While there may be some truth in this statement, I don't think this should be used as a means of avoiding teaching students, especially those like myself who are keen to learn

Sometimes you do feel like your mentor is not enthusiastic about teaching you. I think because being a mentor is seen as compulsory, people should be 
given time away to do mentor duties but in reality this never happens. It makes such a difference when your mentor is enthusiastic and actually remembers what it's like to learn and thinks about what you need.

\section{'It's important to have a strong mentor'}

The following two students suffered from lack of mentorship whereby mentors were absent through sickness, holiday or attendance at meetings. This had consequences on the student learning experience, for example, less opportunity to build relationships and develop confidence. The second student suggested the need for assertiveness in order to find opportunities to learn, a skill she suggests that younger students might not have and subsequently could lead to them feeling daunted in the clinical environment:

My first mentor went off so I was given an associate mentor but they were on holiday for 3 of the remaining 4 weeks so there was no-one there to talk to or work with every single shift... it is not a good learning environment if you work with different people every day, it can be good if you work with someone and find out your own method of learning and build confidence and a relationship

I felt on 2 of my placements that if I was an 18-19 year old with little life experience I would have struggled, as I had to be assertive and seek out opportunities with other teams as my mentor was always in meetings and I never saw her. I think that would have been very daunting for young people in my cohort. 
The following student suggests understaffing as being an influence on learning experiences; leading to a focus on task completion rather than linking theory to the practice:

My mentor was absolutely brilliant, however I do feel that due to understaffing on wards it makes it a lot harder for your mentor to actually spend thorough time teaching you. It is more of just 'this is how you do this, go and do it yourself' instead of actually explaining the reasons behind why they are completing a task in a certain way.

The next two excerpts focus on the personality of the mentor as being important in supporting student learning. The first student has experienced reluctant mentors and suggests mentorship should be a choice for staff and needs to be rewarded. For the second student, having a strong mentor is crucial as mitigation when the learning environment is hostile, although this is not always possible:

A mentor's effectiveness depends completely on their personality, for example if they are interested in helping a student, or if their own time management is effective and therefore [they] can take care of their student. I believe that it should be a nurse's choice to want to become a mentor, perhaps create incentives for them to want to become mentors, because from experience I have known mentors who are reluctant to give enough attention to their student.

Some placements are really unwelcoming with students ... and higher banded staff can be extremely rude and make you feel worthless. Because the 
environment can be unsupportive it is important to have a strong mentor but this often does not happen.

\section{'All they do now is oppress themselves'}

The following excerpts describe negative cultural practices and attitudes witnessed during placement learning experiences. The student in the following excerpt (a third year student who had recently discontinued the programme) overtly describes the issue of nursing oppression and how this led to her discontinuing her studies:

It was such a big important moment when nursing was legitimized as a career, because you know, at one time all nurses were overseen by doctors... but actually all they do now is oppress themselves... even though the ritualized practice has got better... those values of, you know, "Well I wiped arses when I was a student so now you're going to do the same", and, "I had a really mean mentor so I am going to be really mean to you". Actually I thought, do I want to spend the next 60 years of my life doing that? I thought, no, I don't'... and I left...

The next student describes her concerns about the potential of becoming like the staff she meets during clinical placements, suggesting she learns more during campus based study than she does in the practice area:

The one thing that lacks is placements! I find I learn more actually in university than placement. They all seem to contain dark, gloomy, unsatisfied, worn out, 
tired, snappy, over worked, sad, skint staff. And I'm really worried as a student, about ending up like this.

The following students make direct reference to the problems of ineffective leadership and management practices. This has subsequent effects on their learning in terms of poor role modelling and feeling excluded from the clinical placement team:

There was one sister, you never saw her and she was the one person who people seemed to fear rather than respect... and it meant that people would slack when she wasn't around and then there would be a mad rush when she was on the ward... one thing I saw there was one of the care assistants was quite rude about an ethnicity, she was basically racist in front of the sister and the sister didn't do anything about it... I was 21 and that is a really off putting thing to hear and see... I actually had quite a nice mentor but there was only so much she could do.

There were some placements where it felt as if the whole management was dis-organised, simply because the ward did not have that "togetherness/ team spirit", for example in one of my placements the staff were all in cliques which made it really hard for me as a student to fit in.

The following student describes being shouted at by a HCA, in front of patients. A clear episode of negative role modelling that was compounded by the fact that she never received an apology for being treated unfairly: 
She had the attitude that student nurses are too posh to do anything useful but stand around and drink coffee but we had done endless runs to the lab and to pharmacy and every day we would do as we were asked... running around like skivvies and the idea that this woman thought she could just shout at me in a demeaning way in front of patients was really not on... she (mentor) said she would have a word with the woman, who said she would apologise but did she apologise? No, of course not.

In the next excerpt the student describes overt discrimination by qualified staff who describe contemporary degree level education as inferior to the apprentice style approach which they experienced:

I fully respect the credits we take and understand why as a nurse they are so important; but it can be very frustrating being taught all these values and moral obligations and to uphold our professionalism when on placement you feel like you can't fully implement them because other nurses still openly admit they believe degrees are not as good as how they [the nurses] were taught i.e. full-time placement, trained on the job. It can feel awkward sometimes.

\section{DISCUSSION}

The overall aim of this article was to explore the perceived unfairness experienced by student nurses during clinical placements in healthcare settings. Worryingly the emergent themes are similar to those located in existing literature (see for example, Thomas \& Burk, 2009). The behaviour of the practice mentor was important in many 
of the occasions described in this study and indeed mentors have been shown to be essential to the success of student learning in placements (Carr, 2008). Darling (1985) described many of the mentors and staff located in the current research, most notably 'Refusers', those who will not help the student, telling them they can learn that at a later date; 'Avoiders', those who are not available when they should be dealing with the student and 'Withholders'; those mentors who withhold information and skills possibly because it is easier to complete work themselves rather than spend a larger amount of time supporting students to complete the same task.

Some mentors in this study were portrayed as disempowered and weak, indeed there were times when students required them to speak out and show leadership, although this did not always occur and opportunities for positive role modelling were missed. Students described times when the environment was a difficult one in which to work, one where they witnessed poor behaviour. Some HCAs in this study were described as humiliating students either by directly shouting or asking them to complete errands and tasks at the detriment to their learning. As suggested by Mclntosh et al (2014) HCAs often have input into student learning although this is not formally recognized and they do not necessarily receive training and development for this role.

Some students overtly described lack of leadership in the clinical areas and were often left to locate their own learning opportunities which might be difficult for less assertive students, a finding already reported by O'Driscoll et al (2010). Leaving students to seek out their own learning might result in the failure to meet prescribed learning objectives, and ultimately failure of the placement. This is not only upsetting for the student but can lead to threats to patient safety, especially if the student is working unsupervised. 
It would seem then, that students clinical placement experiences are a complex and difficult aspect of nurse education and one which might be challenging to improve given the ongoing issues in the English NHS, in terms of understaffing, reliance on agency staff and increasing pressure on the front line workforce (RCN, 2015). Student nurses desire interesting clinical experiences where they feel valued and supported, however the priority for many NHS staff in this study, is to complete the given tasks for the day, not to be concerned with student support. Smith \& Gray (2001) have suggested matching student nurses with specific mentors, taking into account their unique and individual interests and personalities. Rather than a 'one size fits all' approach to mentoring, there can be an encouragement of relationship building between certain individuals, not only between mentor and student, but involving the whole team. Mentorship does not take place in a vacuum and open and honest exploration of the educational philosophy of the team is important. Cranton (2016: 145) suggested that educators describe their frame of reference by asking questions of themselves including; 'What is my purpose in being an educator'; 'How do I see the learners I work with' and 'What constraints or resistances influence my practice'. In line with a transformative learning process, educators grow in their roles by understanding themselves better whilst at the same time, valuing the unique nature of who they are both as a practitioner and educator.

Based on the data from this study, and relevant contemporary literature discussed earlier, we propose a tiered model as a way of thinking about mentorship for undergraduate student nurses (see figure 1). 
Central to this model are the four qualities of role model, legitimizer, advocate and respecter.

\section{Role-model}

The need for positive nurse role models has been documented over some years in the nursing literature most latterly Jack et al (2017) who explored the influence of both positive and negative role models on students clinical and campus based learning. Positive role models are important for students who value enthusiasm for the nursing role and a caring approach as being important. Our data suggest that there were times when mentors lacked enthusiasm for their role and this might be due to factors beyond their control, for example, being newly qualified and in need of support themselves.

\section{Legitimizer}

Levett-Jones et al (2009) suggest that for students' belongingness to occur there needs to be legitimization of the student role. Student nurses are an important part of the healthcare team, bringing new ideas and insights to the clinical area. Considering teaching and learning as a two way process is important; learning from students is as significant as teaching them. Viewing mentorship as an integral and legitimate use of qualified nurse time, and not an additional extra, is essential although our data suggests that this was not the case on some occasions. The NMC (2008) state that mentors should spend forty percent of their time supervising students either directly or indirectly, but if this is not facilitated by senior staff, it places mentors in a difficult position, between pleasing their superiors on the one hand, and supporting students on the other. This confirms the importance of strategic support for mentorship 
activity, so that it is viewed as a legitimate use of time and students are viewed as important members of the team with a right to be there and have their views heard.

\section{Advocate}

Students rely on mentors to be their advocates and help them to access learning in the clinical area. Indeed the NMC (2008: 26) state that mentors must, "be an advocate for students to support them accessing learning opportunities that meet their individual needs'. Advocacy for students can become even more important especially in the face of difficult experiences such as the witnessing of poor clinical practice. Students worry about raising concerns about practice not least because they are relying on staff to sign them off as competent on completion of the placement (Ion et al, 2017). However if the mentor can legitimize students concerns, this contributes to effective learning and ultimately patient safety. However, through the data it was shown that mentors might not feel confident to advocate on behalf of students, and this might be due to inexperience or fear of reprisals from more senior staff.

\section{Respecter}

It is important for newly qualified nurses to fit in with the predominant culture whether that is positive or negative (Armstrong, 2008) and siding with a student might seem inappropriate and unconducive to their progress. However, respecting students' views and status affirms their sense of belongingness and wellbeing and is important for their confidence and self-esteem. Viewing them as being of lesser status in comparison to apprentice style students undermines the educational experience and leaves students feeling undermined and uncomfortable, especially since they have no control about the style of education they receive. 
Fundamental to these four qualities are both leadership and educational philosophy (the second tier of the model) as the data in this study suggests that, in many of the perceived unfairness episodes described previously, there was a lack of effective leadership and/or underpinning positive learning environment. Promoting leadership capabilities is vital for all staff working in healthcare in England, not just those in senior/managerial roles (NHS Leadership Academy 2016) as essentially all have potential to influence students' experiences. Whilst leadership may be provided outside of the students' immediate placement environment the greatest influence will be gained from those who are most immediately visible. For example, the HCAs featured in the student data, were described as portraying negative behaviours, yet have enormous potential to influence student behaviour through positive role modelling, especially when considering the amount of time they spend with students (see also O'Driscoll et al 2010).

Educational philosophy is also an important factor to consider. This is characterized by the values and beliefs of an organization, grounded in policy, which might be at odds with the reality of practice. Student support exists within the culture of the local environment in which staff operate and if staff are to support and value students then they also need to feel supported and valued within the workplace. Thus values and beliefs, need to be clearly communicated and training and resources need to be readily available to support this.

We suggest that having the described factors inherent within a placement environment will support positive student experiences. However, whilst these are important if a positive mentoring culture is to be fostered we need to look beyond individual mentors and the local environment and consider how national policy and philosophy influence culture - the outer tier of the model. 
None of the factors are of more or less importance although they are placed at different levels, from a macro strategic level, followed by the placement factors, to individual mentor qualities, with the student placed in the centre. We suggest that having the described factors in place will support positive student experiences during clinical placement.

\section{CONCLUSION}

In this study we have explored episodes of perceived unfairness experienced by undergraduate student nurses during their clinical placements. Building on the existing nursing literature and the data from this study we have proposed a tiered model to inform thinking about effective mentorship. This can be viewed as a way of enhancing existing good practice and supporting the targeted development for staff at all grades who contribute to student learning in practice. A collaborative approach between universities, placement staff at all levels and educational providers is required. Students need to feel valued and respected for their contribution to practice. Such an approach is underpinned by effective leadership and a shared enabling educational philosophy. This philosophy must be linked to both professional guidelines and national policy. Building positive relationships across teams of staff can have a huge impact on the students' well-being and is ultimately essential for quality patient care.

\section{RELEVANCE TO PRACTICE}

This study provides further insight into the experiences of student nurses during clinical placements. Specifically it focuses on times when students felt they were being unfairly treated by others; and the data supports the view that an effective 
mentor is crucial to student success. The findings are important in that they highlight some of the factors, which relate to effective mentorship and the learning experiences offered by the wider team. Being treated unfairly can leave students feeling disheartened and in some cases, as shown through this data, can contribute to them leaving the profession. Based on the data from this study and other contemporary literature we propose a way of thinking which takes into account the factors needed for success at different levels. Understanding what is important to students and how vulnerable they are in the practice setting can support changes in thinking about mentor and team support. Ultimately this can support a change in the social nursing culture into a more positive one than has been reported in the paper.

\section{What does this paper contribute to the wider global clinical community?}

The findings of this study demonstrate on-going concern about student nurses' learning experiences. The implications of such poor experiences are analysed.

Perceived unfair incidents can have a detrimental effect on learning in the clinical environment

A tiered mentorship model is presented which describes the strategic factors and personal qualities required to support effective placement learning

\section{REFERENCES}

Armstrong, N. (2008). Role modelling in the clinical workplace. British Journal of Midwifery. 16(9), 596-603. DOI: http://dx.doi.org/10.12968/bjom.2008.16.9.30888. 
Beauvais, A.M., Stewart, J.G., DeNisco, S., Beauvais, J.E. (2014). 'Factors related to academic success among nursing students: A descriptive correlational research study.' Nurse Education Today. 34(6), 918-923. DOI: 10.1016/j.nedt.2013.12.005.

Bowden, J., (2008) Why do nursing students who consider leaving stay on their courses? Nurse Researcher, 15(3), 45-58. DOI: 10.7748/nr2008.04.15.3.45.c6456

Bradbury-Jones C., Sambrook, S., \& Irvine, F. (2011). Empowerment and being valued: A phenomenological study of nursing students experiences of clinical practice. Nurse Education Today. 31, 368 - 372.

DOI: http://dx.doi.org/10.1016/j.nedt.2010.07.008.

Brodie, D. A., Andrews, G. J., Andrews, J. P., Thomas, G. B., Wong, J. and Rixon, L. (2004). Perceptions of nursing: confirmation, change and the student experience. International Journal of Nursing studies. 41(7), 721-733. DOI: 10.1016/j.jinurstu.2004.02.009.

Carr, G. (2008). Changes in nurse education: delivering the curriculum Nurse Education Today. 28(1), 120 - 127. DOI: 10.1016/j.nedt.2007.03.011.

Cranton, P. (2016). Understanding and Promoting Transformative Learning: A guide to theory and practice. Virginia: Stylus.

Crombie, A., Brindley, J., Harris, D., Marks-Maran, D., Morris Thompson, T. (2013) 'Factors that enhance rates of completion: What makes students stay?' Nurse Education Today. 33(11), 1282-1287. DOI: 10.1016/j.nedt.2013.03.020.

Curtis, J., Bowen, I., \& Reid, A. (2007). You have no credibility: Nursing students' experiences of horizontal violence. Nurse Education In Practice. 7, 156 - 163. DOI: 10.1016/j.nepr.2006.06.002. 
Daiski, I. (2004). Changing nurses' dis-empowering relationship patterns. Journal of Advanced Nursing. 48, 43 - 50. DOI: 10.1111/j.1365-2648.2004.03167.x.

Darling, L.A.W. (1985). What to do about toxic mentors. Journal of Nursing Administration. 15, 43-44.

Francis, R. (2015). Freedom to speak up: An Independent Review into Creating an Open and Honest Reporting Culture in the NHS

\section{http://freedomtospeakup.org.uk/wp-content/uploads/2014/07/F2SU web.pdf}

Last accessed 15/4/17.

Gubrium, J.F. (1993). Speaking of Life Horizons of meaning for nursing home residents. New York: Aldine de Gruyter.

Hall, C. (2004). Young nurses too posh to wash?

http://www.telegraph.co.uk/news/uknews/1461504/Young-nurses-too-posh-towash.html Last accessed 17/4/17.

Hamshire, C., Willgoss, T.G., Wibberley, C. (2011). 'The placement was probably the tipping point'. The narratives of recently discontinued students.' Nurse Education in Practice, 12(4), 182-186. DOI: 10.1016/j.nepr.2011.11.004.

Hamshire, C., Wilgoss, T.G., \& Wibberley, C. (2013a). Should I stay or should I go? A study exploring why healthcare students consider leaving their programme. Nurse Education Today. 33(8), 889 - 895. DOI: 10.1016/j.nedt.2012.08.013.

Hamshire, C., Willgoss., T.G., Wibberley, C. (2013b). What are reasonable 
expectations? Healthcare student perceptions of their programmes in the North West of England. Nurse Education Today. 33(2), 173-179. https://doiorg.ezproxy.mmu.ac.uk/10.1016/j.nedt.2012.02.014.

Hamshire, C., Barrett, N., Langan, M., Harris, E \& Wibberley, C. (2017). Students' perceptions of their learning experiences: a repeat regional survey of healthcare students. Nurse Education Today. 49, 168 - 173.

http://dx.doi.org/10.1016/j.nedt.2016.11.019.

Ion, R., Smith, K. \& Dickens, G. (2017). Nursing and Midwifery Students' encounters with poor clinical practice: A systematic review. Nurse Education in Practice. 23, 67 75. https://doi-org.ezproxy.mmu.ac.uk/10.1016/j.nepr.2017.02.010.

Jack, K. \& Wibberley, C. (2014). The meaning of emotion work to student nurses: A Heideggerian analysis. International Journal of Nursing Studies. 51(6), 900 - 907. https://doi.org/10.1016/j.ijnurstu.2013.10.009.

Jack, K., Hamshire, C. \& Chambers, A. (2017). The Influence of Role Models in Undergraduate Nurse Education. Journal of Clinical Nursing. Corrected proof in press. DOI: 10.1111/jocn.13822.

Jones-Schenk, J., Harper, M.G. (2014). 'Emotional intelligence: An admission criterion alternative to cumulative grade point averages for pre-licensure students. Nurse Education Today. 34(3), 413-420. DOI: 10.1016/j.nedt.2013.03.018.

Knight, J., Corbett, A., Smith., C, Watkins, B., Hardy., R \& Jones, G. (2012) "What made me stay" A review of the reasons student nurses enrolled in a Bachelor of Nursing programme completed their studies: A descriptive phenomenological study 
Nurse Education Today 32(8), e32 - e65. DOI:

https://doi.org/10.1016/j.nedt.2012.03.007

Levett-Jones, T. \& Lathlean, J. (2008). Belongingness: A prerequisite for nursing students' clinical learning. Nurse Education in Practice, 8(2), 103-111. DOI:

10.1016/j.nepr.2007.04.003.

Levett-Jones, T. \& Bourgeois, S. (2008) .The Clinical Placement: A Nursing Survival Guide Oxford: Elsevier.

Levett-Jones, T., Lathlean, J., Higgins, I. \& McMillan, M. (2009). Staff-student relationships and their impact on nursing students' belongingness and learning. Journal of Advanced Nursing. 65(2), 316 - 324. DOI: 10.1111/j.13652648.2008.04865.x.

McIntosh, A., Gidman, J. \& Smith, D. (2014). Mentors' perceptions and experiences of supporting student nurses in practice. International Journal of Nursing Practice. 20, 360 - 365. DOI: 10.1111/ijn.12163.

Meissner, J.E. (1986). Nurses are we eating our young? Nursing. 16, 51 - 53.

National Health Service Leadership Academy. (2016). Developing People Improving Care http://www.leadershipacademy.nhs.uk/news/developing-peopleimproving-care/ Accessed 2/5/17

National Health Service Improvement (2016) Evidence from NHS Improvement on Clinical Staff Shortages: A workforce analysis NHS Improvement: London

Nicoreta, A.M. \& Clinkscales, M.C. (2010). Nurses at the nexus: A case study in structurational divergence. Health Communication. 25, 32 - 49. http://dx.doi.org/10.1080/10410230903473516. 
Nursing and Midwifery Council. (2010). Standards for Pre-Registration Nursing Education. NMC: London.

Nursing and Midwifery Council. (2008). Standards to support learning and assessment in practice. NMC: London.

O'Driscoll, M.F., Allan, H.T. \& Smith, P.A. (2010). Still looking for leadership - Who is responsible for student nurses' learning in practice? Nurse Education Today. 30, 212 - 217. DOI: 10.1016/j.nedt.2009.12.012.

Randle, J. (2002). Transformative Learning: Enabling Therapeutic Nursing in Freshwater D (ed) Therapeutic Nursing. London: Sage.

Randle, J. (2003). Bullying in the nursing profession. Journal of Advanced Nursing. 43, 395 - 401. DOI: 10.1046/j.1365-2648.2003.02728.x.

Ritchie J \& Spencer L (1994) Qualitative Data Analysis for Applied Policy Research In Bryman \& Burgess RG (Eds) Analyzing Qualitative Data London Taylor \& Francis

Ritchie, J., Lewis, J., McNaughton Nicholls, C. \& Ormston, R. (2013). Qualitative Research Practice. London: Sage.

Roberts, S.J. (1983). Oppressed group behaviour: Implications for nursing. Advances in Nursing Science. 5, $21-30$. 
Royal College of Nursing. (2015). A workforce in crisis? The UK nursing labour market review 2015. RCN: London.

Saarikoski, M., Marrow, C., Abreu, W., Riklikiene, O. \& Ozbicakci, S. (2007). Student nurses experiences of supervision and mentorship in clinical practice: a cross cultural perspective. Nurse Education in Practice. 7(6), 407 - 415. DOI: 10.1016/j.nepr.2007.02.006.

Sandelowski, M. (1993). Rigor or rigor mortis: The problem of rigor in qualitative research revisited Advances in Nursing Science. 16, 1 - 8. DOI:

$10.1097 / 00012272-199312000-00002$

Smith, P. \& Gray, B. (2001). Reassessing the concept of emotional labour in student nurse education: role of link lecturers and mentors in a time of change. Nurse Education Today. 21, 230 - 237. DOI: 10.1054/nedt.2001.0541.

Srivastrava, A. \& Thomson, S.B. (2009). Framework Analysis: A Qualitative Methodology for Applied Policy Research. Journal Of Administration and Governance. 4(2), $72-79$.

Thomas, S.P. \& Burk, R. (2009). Junior nursing students' experiences of vertical violence during clinical rotations. Nursing Outlook. 57(4), 226 - 231. DOI: 10.1016/j.outlook.2008.08.004. 
Thomas, J., Jinks, A. \& Jack, B. (2015). Finessing Incivility: The professional socialisation experiences of student nurses' first clinical placement, a grounded theory. Nurse Education Today. 35(12), e4 - e9. DOI: 10.1016/j.nedt.2015.08.022.

Timmins, F. \& Kaliszer, M. (2002). Aspects of nurse education programmes that frequently cause stress to nursing students - fact finding sample survey. Nurse Education Today. 22(3), 203-211. DOI: 10.1054/nedt.2001.0698.

Williams, A. \& Nussbaum, J.F. (2001). Intergenerational communication across the lifespan. New Jersey: Lawrence Erlbaum Associates.

Williamson, G.R., Heath, V. \& Proctor-Childs, T. (2013). 'Vocation, friendship and resilience: a study exploring nursing student and staff views on retention and 
